\title{
A case study integrating numerical simulation and GB-InSAR monitoring to analyze flexural toppling of an anti-dip slope in Fushun open pit
}

\author{
Zhao Li ${ }^{\mathrm{a}}$, Jin'an Wang ${ }^{\mathrm{b}}$, Lin $\mathrm{Li}^{\mathrm{c}}$, Lixiang Wang ${ }^{\mathrm{d}}$, Robert Y. Liang ${ }^{\mathrm{a}, *}$ \\ a Department of Civil Engineering, The University of Akron, Akron, OH 44325-3905, United States \\ b School of Civil and Environmental Engineering, University of Science and Technology Beijing, Beijing 100083, China \\ c Geotechnical Engineer, AECOM, 1375 Euclid Avenue Suite 600, Cleveland, OH 44115, United States \\ d Institute of Mechanics, Chinese Academy of Sciences, Beijing 100190, China
}

\section{A R T I C L E I N F O}

\section{Article history:}

Received 21 January 2015

Received in revised form 31 July 2015

Accepted 9 August 2015

Available online 12 August 2015

\section{Keywords:}

Flexural toppling

Anti-dip slope

Numerical modeling

CDEM

GB-InSAR

Monitoring

\begin{abstract}
A B S T R A C T
Toppling failure of rock slopes is a complicated mode due to a combination of both continuous and discontinuous deformation, especially in dealing with anti-dip rock slopes. In this paper, a novel continuum-based discrete element method (CDEM), which is useful in modeling the entire progressive process from continuous to discontinuous deformation, is proposed to analyze the deformation characteristics, the failure mechanism and the evolution process of a large-scale open pit slope with a typical anti-dip structure. To simulate the slope deformation, the shear strength reduction method (SSR) is adopted to represent the strength degradation of rock mass in the deterioration process. The simulated results are validated using data obtained from a field investigation and continuous monitoring by employing an advanced remote sensing technique called ground-based interferometric synthetic aperture radar (GB-InSAR). To analyze the evolution trend of the anti-dip slope, the subsequent toppling failure mode is predicted using the validated CDEM models. Based on a case study of a slope at the Fushun open pit mine (in Fushun, China), the unique geological structure with various joints and discontinuities, groundwater, intense rainfall, and mining activities are identified as the main triggers for different failure stages. The comparison between the field data and the simulation shows that CDEM accurately depicts the rock deformation and the failure pattern of the studied slope. The proposed numerical modeling techniques can be used for predicting failures of other similar excavated rock slopes. The simulated evolution process and the recorded deformation patterns help engineers to gain a better understanding of rock mass movement of anti-dip slopes, and the presented methodology could be utilized for similar studies and engineering designs.
\end{abstract}

(c) 2015 Elsevier B.V. All rights reserved.

\section{Introduction}

Toppling is a widespread phenomenon in both natural and excavated stratified anti-dip rock slopes. It is a mass movement of rock on a slope characterized by downslope overturning, which can involves flexure, rotation and interaction of rock blocks (Pritchard and Savigny, 1990; Alejano et al., 2010). Toppling has been commonly classified into four principal types: block toppling, flexural toppling, blockflexural toppling, and secondary toppling (Goodman and Bray, 1976). The toppling process can be triggered by natural factors (rainfalls, earthquakes, etc.) (Hack et al., 2007) as well as human engineering activities (Pritchard and Savigny, 1990; Tu et al., 2007; Huang et al., 2013), and it can pose a serious hazard.

A detailed overview of current methods for the analysis of toppling failure has been summarized by Pritchard and Savigny (1990), who

\footnotetext{
* Corresponding author.

E-mail addresses: zl28@zips.uakron.edu (Z. Li), wja@ustb.edu.cn (J. Wang), lin.li02@aecom.com (L. Li), omega168@163.com (L. Wang), rliang@uakron.edu (R.Y. Liang).
}

divided the techniques into three major types. The first type is the limit-equilibrium method (Goodman and Bray, 1976; Aydan and Kawamoto, 1992; Amini et al., 2009), which is a simple but robust analytical technique for predicting toppling. The second type is physical modeling, which includes the base friction model (Bray and Goodman, 1981), the tilt table model (Wong and Chiu, 2001) and the centrifuge model (Adhikary et al., 1997; Adhikary and Dyskin, 2007). The third type is numerical modeling; these methods include the finite element method (FEM) and discrete element method (DEM), which have been employed to model the toppling of layered rock slopes (Pritchard and Savigny, 1990; Adhikary et al., 1996; Adhikary and Dyskin, 2007; Alejano et al., 2010).

The researchers mentioned above have contributed to an understanding of the mechanism of the flexural toppling failure mode. Briefly, the mechanism for toppling failure can be described by the following process. Under gravity, the interacting rock layers tend to bend toward the excavation side, resulting in different degrees of deflection of the rock layers; this leads to mutual sliding and dislocation, and finally a bending (tensile) stress is induced. Once the bending stress exceeds the tensile strength of the rock layers, fracturing of rock layers will be 
initiated (Aydan and Kawamoto, 1992; Adhikary et al., 1996; Adhikary and Dyskin, 2007; Amini et al., 2009). Thus, flexural toppling failure is a progressive process that changes from continuous deformation to discontinuous deformation. However, in terms of the distinctive deformation characteristics of flexural toppling, traditional numerical methods for analyzing toppling cannot account for both the mechanism. Therefore, a suitable numerical simulation method is urgently needed for better modeling of the evolution process and interpretation of the mechanism of toppling.

This study introduces the continuum-based discrete element method (CDEM), a novel numerical method that is a combination of both FEM and DEM and was originally proposed by Li et al. (2004a). The theoretical basis of CDEM has been thoroughly validated against analytical solutions and experimental results (Li et al., 2004a, 2005, 2007). In this paper, the results of CDEM analyses are verified by the on-site slope deformation and the results of continuous monitoring of the slope by using a state-of-the-art remote sensing apparatus that is part of an integrated monitoring platform. The platform, which consists of groundbased interferometric synthetic aperture radar (GB-InSAR) and an automatic digital camera, was installed in front of the open-pit slope to collect data continuously under all weather conditions (Bozzano et al., 2008, 2011). Similar SAR techniques have been verified as effective and precise for monitoring and detecting surface deformation (Colesanti and Wasowski, 2006; Herrera et al., 2007; Fernandez et al., 2009; Perski et al., 2009; Tomas et al., 2010).

In this paper, the evolution process and the failure mechanism of flexural toppling is investigated in the northern slope of the Fushun open pit in Fushun, China. The main objectives of this study are to: (1) introduce CDEM for modeling the toppling deformation process of an anti-dip slope; (2) utilize real monitoring data to check the validity of the CDEM analyses; and (3) examine the observed displacement and deformation patterns in order to gain greater insight into the overall long-term dynamic evolution of flexural toppling of a given anti-dip slope.

\section{Continuum-based discrete element method (CDEM)}

CDEM is a coupled finite/discrete element method that has been used for a wide variety of applications (Wang et al., 2013). In this study, CDEM is adopted to consider the distinctive deformation characteristics of a toppling mode. Not only is CDEM able to simulate deformation in the continuous state and motion behavior in the discontinuous state, but it can also achieve the progressive failure evolution of materials from a continuous state to a discontinuous state. A brief description of CDEM is provided in this section.

\subsection{Computational model}

CDEM consists of two kinds of elements: a block and a contact. As shown in Fig. 1, CDEM is a combination of FEM and DEM; FEM is used within the block, and DEM is used for the interface between two adjacent blocks. A discrete block can be composed of one or more finite elements. The three major types of finite element in CDEM are a fournode tetrahedron, a six-node wedge, and an eight-node hexahedron (Wang et al., 2013). A three-dimensional (3-D) contact, which connects two nodes of neighboring blocks, contains three joint springs. One spring is in the normal direction, and the other two are in the tangential direction. A two-dimensional (2-D) contact contains one normal spring $\left(k_{n}\right)$ and one tangent spring $\left(k_{s}\right)$ (Wang et al., 2013), which is indicated in Fig. 2. These springs are orthogonal to each other, and their characteristics are the same as the DEM (Li et al., 2004b). The evolution from continuous deformation to discontinuous deformation is simulated by the breakage of springs, which can occur if the tensile strength is reached. The Mohr-Coulomb Law is applied on the interface (Li et al., 2007); with these contacts, the discontinuous deformation between blocks can be achieved. CDEM can more accurately describe the micro-failure process because each node has a greater number of springs (Wang et al., 2005).

\subsection{Computation procedure}

Each block in the model has two external forces: the body force and the contacting force from neighboring blocks. The governing kinetic equation for each element is based on Newton's Second Law of Motion:

$\mathbf{M} \overrightarrow{\mathbf{a}}+\mathbf{C} \overrightarrow{\mathbf{v}}+\mathbf{K} \overrightarrow{\mathbf{u}}=\overrightarrow{\mathbf{F}}_{e x t}$

where, $\overrightarrow{\mathbf{u}}, \overrightarrow{\mathbf{v}}$, and $\overrightarrow{\mathbf{a}}$ are the displacement vector, velocity vector and acceleration vector, respectively; $\mathbf{M}$ is the mass matrix; $\mathbf{C}$ is the damping matrix; $\mathbf{K}$ is the stiffness matrix; and $\overrightarrow{\mathbf{F}}_{\text {ext }}$ is the vector of external force. The contacting forces, which are simulated by springs, are calculated using Eq. (2).

$$
\left\{\begin{array}{l}
F_{n}^{j}=-K_{n}^{j} \Delta u_{n}^{j} \\
F_{s}^{j}=-K_{s}^{j} \Delta u_{s}^{j}
\end{array}\right.
$$

where $F_{n}^{j}, F_{S}^{j}$ stand for the normal force and tangential force of spring $j$; $K_{n}^{j}$ and $K_{s}^{j}$ are the normal stiffness and tangential stiffness of spring $j$, respectively; and $\Delta u_{n}^{j}$ and $\Delta u_{s}^{j}$ are the relative normal displacement and tangential displacement of spring $j$, respectively.

The dynamic relaxation method is used to solve the kinetic equation. Thus, the element stiffness matrix is required rather than the global stiffness matrix. The element stiffness matrix is the same as that of the FEM if the material is a continuum (Li et al., 2004a). Nodal forces are calculated by Eq. (3) and are allocated to the corresponding nodes.

$\overrightarrow{\mathbf{F}}_{i}^{e}=\mathbf{K}_{i}^{e} \overrightarrow{\mathbf{u}}_{i}^{e}$

where $\overrightarrow{\mathbf{F}}_{i}^{e}$ is the nodal force vector for element $i, \overrightarrow{\mathbf{u}}_{i}^{e}$ is the nodal displacement vector for element $i$, and $\mathbf{K}_{i}^{e}$ is the stiffness matrix for element $i$.

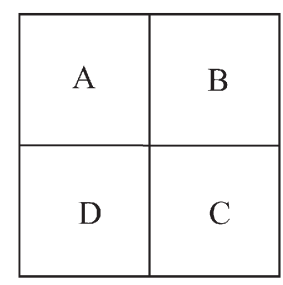

(a) FEM

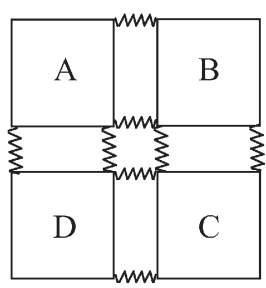

(b) DEM

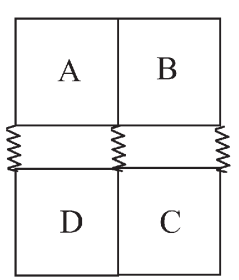

(c) CDEM

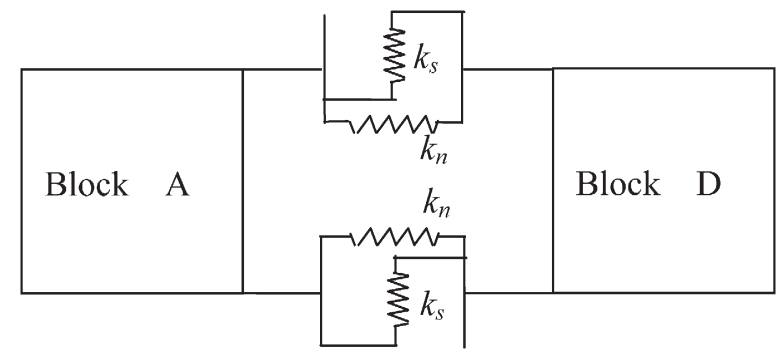

Fig. 2. 2-D CDEM contact.

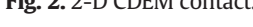

Fig. 1. Comparison of geometric domains a) FEM; b) DEM; and c) CDEM. 


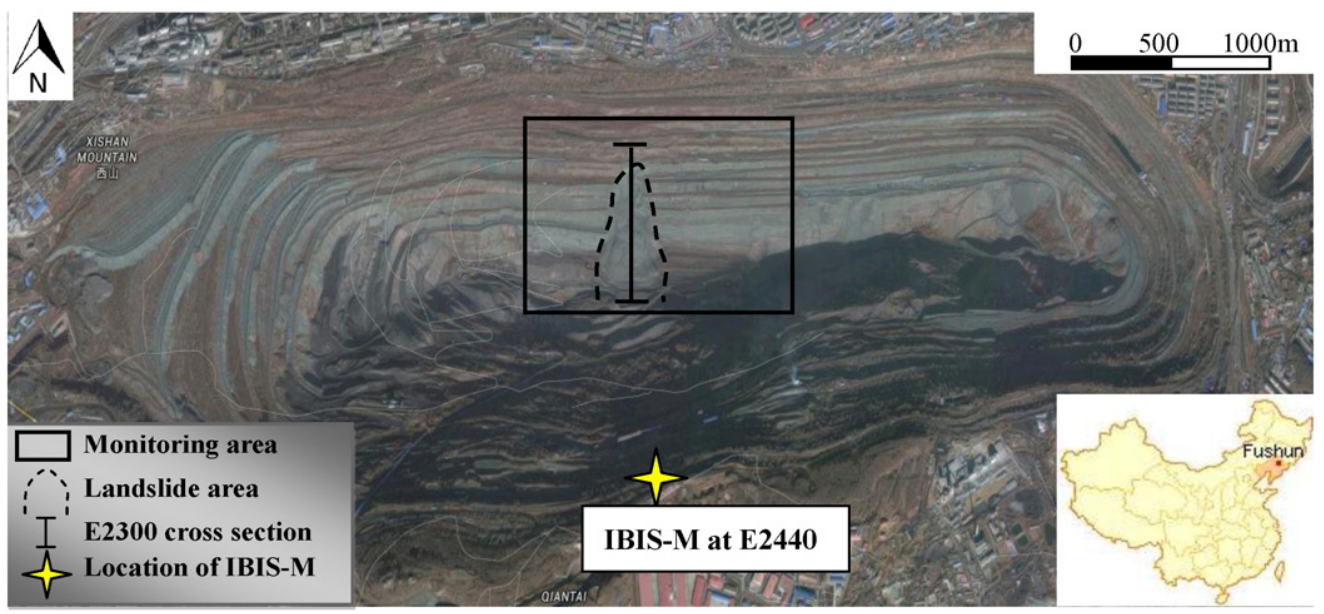

Fig. 3. Satellite map of Fushun open pit (Fushun, China), April, 2015.

CDEM is a process of iterative calculation, which can be summarized in the following steps:

Step 1 Set initial nodal acceleration, velocity and displacement.

Step 2 Calculate external force $\overrightarrow{\mathbf{F}}_{\text {ext }}$, including tractions and body force. Step 3 Compute internal nodal force and damping force $\overrightarrow{\mathbf{F}}_{\text {int }}=\mathbf{K} \overrightarrow{\mathbf{u}}+$ $\mathbf{C} \overrightarrow{\mathbf{v}}$ (for static problems $\overrightarrow{\mathbf{F}}_{\text {int }}=\mathbf{K} \overrightarrow{\mathbf{u}}$ ).

Step 4 Calculate the nodal force, $\overrightarrow{\mathbf{F}}_{\text {nod }}=\overrightarrow{\mathbf{F}}_{\text {ext }}-\overrightarrow{\mathbf{F}}_{\text {int }}$.

Step 5 Compute acceleration by Newton's Second Law: $\overrightarrow{\mathbf{a}}=\mathbf{M}^{-\mathbf{1}} \overrightarrow{\mathbf{F}}_{\text {nod }}$. Step 6 Compute the nodal velocity and displacement: $\overrightarrow{\mathbf{v}}=\overrightarrow{\mathbf{a}} d t, \overrightarrow{\mathbf{u}}=$ $\overrightarrow{\mathbf{v}} d t$, where $d t$ is the time step.

Step 7 Repeat Steps 2 to 6 until the total kinetic energy, $E_{k}=\sum \frac{1}{2} \overrightarrow{\mathbf{v}}^{T} \overrightarrow{\mathbf{v}}$, is reduced to an infinitesimal value (Wang et al., 2013).

\subsection{CDEM performance}

The performance of CDEM has been verified by theoretical solutions and physical modeling. For instance, the application of CDEM was verified in this manner by modeling rock mass under uniaxial loading ( $\mathrm{Li}$ et al., 2004b). In this study, the numerical results were consistent with theoretical calculations and experimental observations in both deformation process and failure process. Moreover, synthetic jointed rock slopes have also been successfully analyzed by using the CDEM method (Li et al., 2005, 2007). The toppling failure modes predicted by CDEM have been proved to be in good agreement with laboratory tests. Particularly, CDEM has been successfully and efficiently used to simulate and analyze the occurrence and development of landslide of a rock slope in Panluo opencast mine (Zhang et al., 2005).

Generally speaking, CDEM could well simulate the failure state of rock slope regardless of joint distribution and size effect (Li et al., 2005 , 2007). Also, by implementing a graphics processing unit (GPU)based parallel computation technique, CDEM is able to undertake large-scale computing tasks with a huge number of elements (Wang et al., 2013). However, CDEM has its limitations. CDEM could reproduce the sliding failure mode, but it cannot estimate the sliding distance of rock mass well. However, this problem is beyond the scope of this paper.

\section{Engineering geology}

The Fushun open pit (Fig. 3) is located about $47 \mathrm{~km}$ east of Shenyang, the capital city of Liaoning Province, at longitude $123^{\circ} 49^{\prime} 11^{\prime \prime}-123^{\circ} 55^{\prime}$ $23^{\prime \prime}$ and latitude $41^{\circ} 49^{\prime} 40^{\prime \prime}-41^{\circ} 51^{\prime} 23^{\prime \prime}$. It is situated between the Hun River and Longgang Mountains in Changbai Mountain Range, on a narrow plain that has a moderate terrain and low altitude (the ground
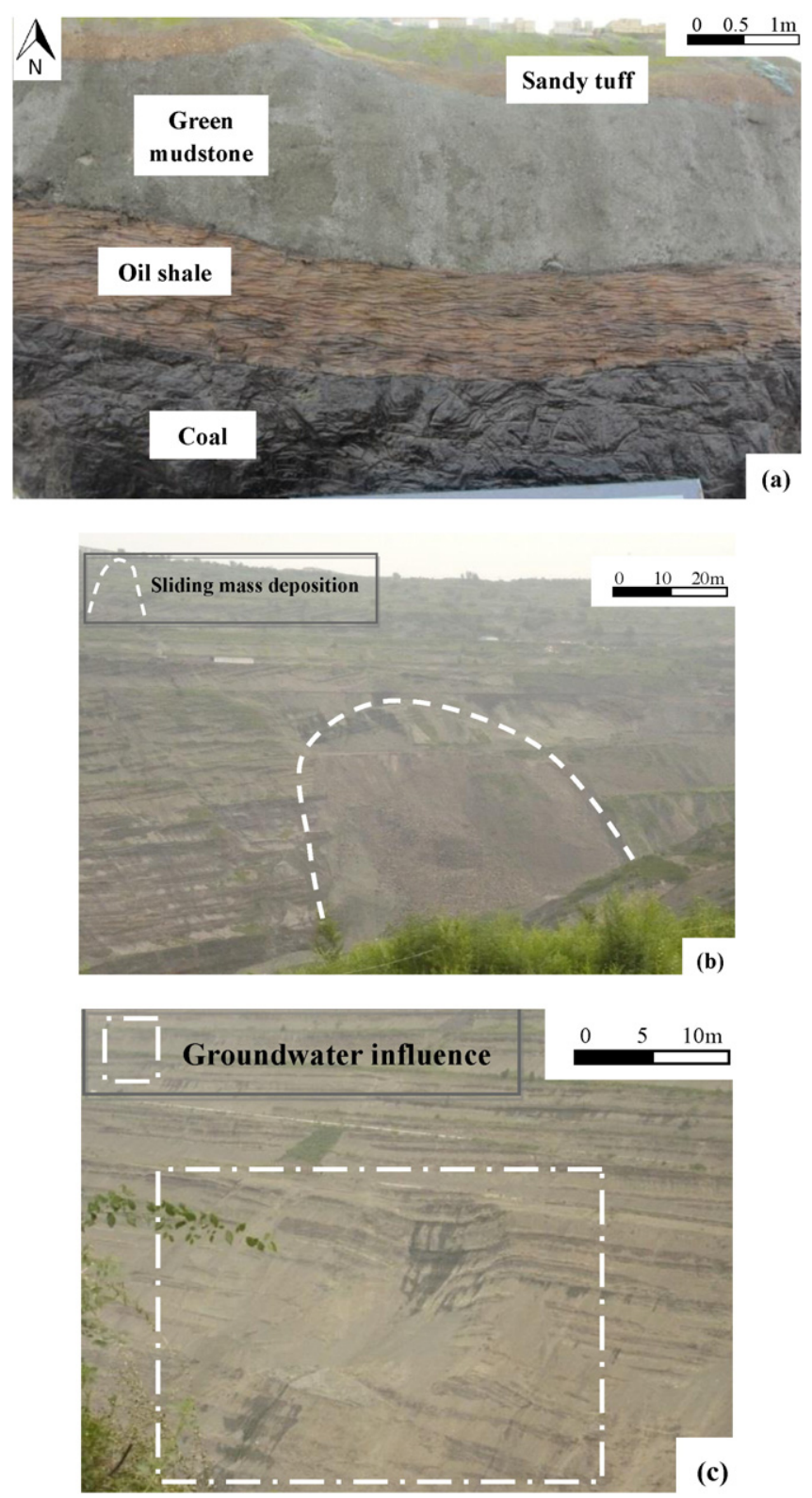

Fig. 4. Field observations of the northern wall of Fushun open pit (July, 2012): a) layers of stratification; b) sliding mass deposition; and c) groundwater influence. 


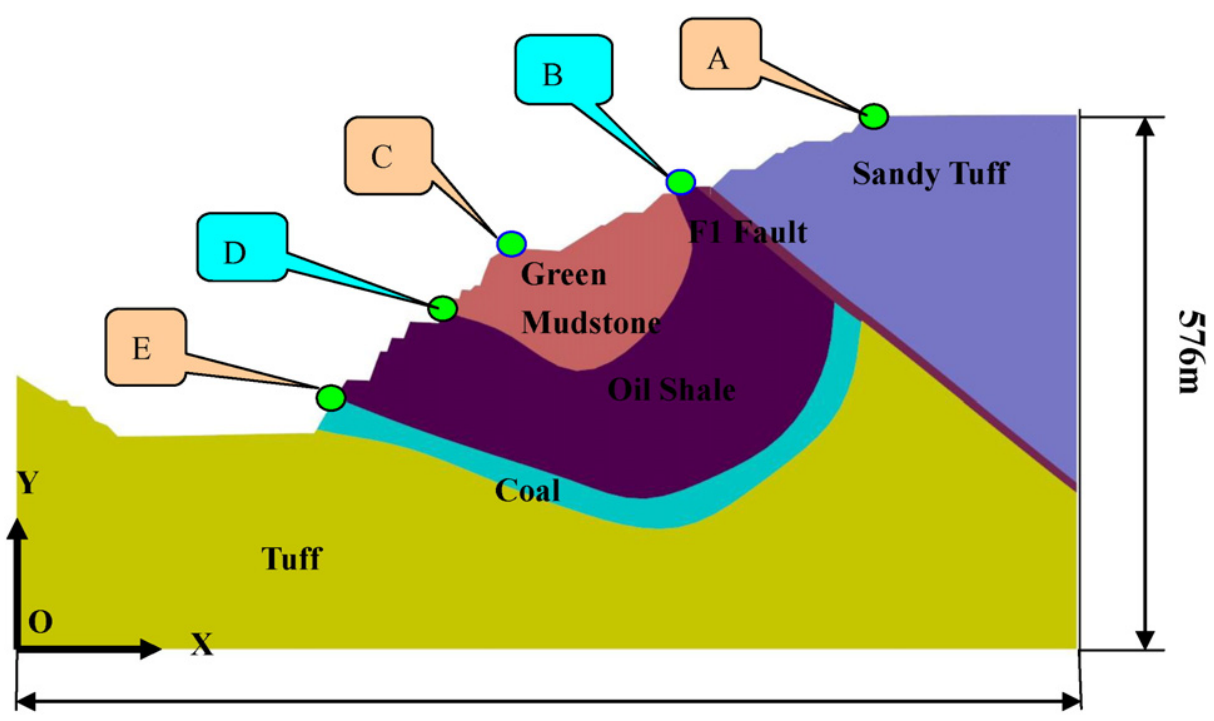

$1100 \mathrm{~m}$

Fig. 5. Numerical model and monitoring points.

elevation ranges from $70 \mathrm{~m}$ to $80 \mathrm{~m}$ above the sea level). The general trend of the terrain is slightly higher in the northeast and lower in the southwest, with a gradient of $2 \%$. The mine pit is $6.6 \mathrm{~km}$ at its widest point from east to west and $2.2 \mathrm{~km}$ at its widest point from north to south, covering an area of $11.0 \mathrm{~km}^{2}$. The lowest elevation point of the west portion of the mine pit is $-335 \mathrm{~m}$ with an average of $-290 \mathrm{~m}$, and the lowest elevation point of the east portion is $-200 \mathrm{~m}$ with an average of $-185 \mathrm{~m}$. The coal seam trends in an approximately eastwest direction, dipping to the north with a slope gradient from $230^{\circ}$ to $300^{\circ}$, with an average of $260^{\circ}$. The thickness of the coal seam ranges from $30 \mathrm{~m}$ to $145 \mathrm{~m}$, with an average of $55.5 \mathrm{~m}$. The roof of the coal seam consists of oil shale and tuff.

The northern slope of Fushun open pit, which has a height in the range of 300 to $400 \mathrm{~m}$, experienced significant toppling deformation when cut at approximately $50^{\circ}$. Since the mining is carried out deep within the steep slope, high stability for the northern slope is required. Hence, the geological setting of this area and characteristics of the northern slope are reported herein in order to provide a better understanding of the deformation mechanism.

Three main geological features are found in the northern slope of Fushun open pit. The first one is a synclinal coalfield basin. The synclinal axis strikes roughly east-west with nearly symmetrical wings. The core of synclinal basin is green mudstone, and the wings are oil shale, coal, and tuff. The second feature is the F1 fault, which trends to $\mathrm{N} 80^{\circ} \mathrm{E}$ and dips to NNW with a range of $45^{\circ}$ to $55^{\circ}$. The F1 fault is several meters wide. The upper plate of the F1 fault is sandy tuff, and the lower plate includes tuff, coal, oil shale and green mudstone. Additionally, due to the F1 fault, a traction fold zone was formed with crushed rocks, joints, and discontinuities in the lower plate of the F1 fault, and the primary structural planes are oil shale joints and green mudstone joints.

Table 1

The main physical parameters of rock mass.

\begin{tabular}{lllllll}
\hline Rock name & $\begin{array}{l}\text { Bulk } \\
\text { density } \\
\left(\mathrm{kg} / \mathrm{m}^{3}\right)\end{array}$ & $\begin{array}{l}\text { Elastic } \\
\text { modulus } \\
(\mathrm{MPa})\end{array}$ & $\begin{array}{l}\text { Poisson } \\
\text { ratio } \mu\end{array}$ & $\begin{array}{l}\text { Tensile } \\
\text { strength } \\
(\mathrm{MPa})\end{array}$ & $\begin{array}{l}\text { Cohesion } \\
(\mathrm{MPa})\end{array}$ & $\begin{array}{l}\text { Friction } \\
\text { angle } \\
\left({ }^{\circ}\right)\end{array}$ \\
\hline Green mudstone & 2200 & 1200 & 0.24 & 1.25 & 1.25 & 35 \\
Oil shale & 2100 & 3400 & 0.26 & 1 & 1.9 & 33 \\
Coal & 1300 & 1200 & 0.3 & 0.8 & 1.25 & 35 \\
Tuff & 2400 & 10,500 & 0.23 & 2.15 & 4.5 & 45 \\
Sandy tuff & 2600 & 6000 & 0.28 & 1.5 & 3.75 & 43 \\
\hline
\end{tabular}

The rock mass in the northern slope has several structural characteristics. The granular structure, which consists of Quaternary alluvium, is located at the top of slope, with the bottom elevation of $+58 \mathrm{~m}$ to $+62 \mathrm{~m}$. Moreover, a granular-cracked structure composed of tectonic breccias, cataclasite and fault gouge is located around the F1 fault. Furthermore, the northern slope has an anti-dipped stratified structure with the synclinal axis of the coal seam. The north-dipping layered strata include green mudstone, oil shale, coal and other rocks, with a slope gradient of $200^{\circ}$ to $250^{\circ}$.

\section{Methodology}

Prior to analyzing the open pit northern slope, a field investigation was first carried out. Next, a number of numerical simulations were conducted with CDEM to evaluate the stability of the slope and to explore the evolution of flexural toppling. The numerical results were compared to the real monitoring results obtained from GB-InSAR and the field observations. A subsequent qualitative analysis was undertaken to deduce the toppling failure mechanism of this open pit slope according to the numerical results and the monitoring results, taking into consideration the geological characteristics of this region, the effects of natural factors, and the impacts of mining operation. Finally, the toppling evolution trend was predicted based on the present conditions at the site.

\subsection{Field investigation}

The field investigation involved a review of existing hydrogeological data, systematic collection of field data, and obtaining engineering properties of the rock at the site. A number of site investigations were undertaken to reveal the geological features, the structural characteristics, and the deformation attributes of the northern slope, as well as to determine any environmental issues in the study area. Fig. 4 shows photographs of the northern wall of Fushun open pit. As can be seen in these photographs, the rock mass was formed in layers dipping into the slope. A unique anti-dipping hard stratum (sandy tuff) overlies the soft rock strata (green mudstone and oil shale), and a coal seam is found at the bottom of the slope (Fig. 4a). Fig. 4b illustrates the sliding mass deposition and Fig. 4c indicates that the slope is influenced by groundwater. According to the hydrogeological materials (Yang et al., 2004), the groundwater level is $25 \mathrm{~m}$ below the ground surface, and it varies in the flood season. 
Table 2

The main physical parameters of F1 fault.

\begin{tabular}{llllll}
\hline $\begin{array}{l}\text { Fault } \\
\text { name }\end{array}$ & $\begin{array}{l}\text { Normal } \\
\text { stiffness } \\
(\mathrm{MPa} / \mathrm{m})\end{array}$ & $\begin{array}{l}\text { Shear } \\
\text { stiffness } \\
(\mathrm{MPa} / \mathrm{m})\end{array}$ & $\begin{array}{l}\text { Friction } \\
\text { angle } \\
\left({ }^{\circ}\right)\end{array}$ & $\begin{array}{l}\text { Cohesion } \\
(\mathrm{MPa})\end{array}$ & $\begin{array}{l}\text { Tensile } \\
\text { strength } \\
(\mathrm{MPa})\end{array}$ \\
\hline $\mathrm{F}_{1}$ & 2200 & 1500 & 26 & 0.4 & 0.0001 \\
\hline
\end{tabular}

\subsection{Numerical simulation with CDEM}

After collecting information from the field investigation, the open pit slope was evaluated to determine its stability and examine how its geological characteristics provoke instability under natural and human impacts. For these reasons, a number of numerical simulations by CDEM were performed to imitate the toppling propagation. It is worth noting that for the problem of flexural toppling, the rock layers exhibit bending behavior that is similar to that of cantilever beams. The CDEM results of a cantilever beam subjected to external load have been verified by $\mathrm{Li}$ et al. (2004a).

Based on the geological profile obtained for the northern wall of the Fushun Open Pit, the numerical model was set up (Fig. 5) to simulate the cross-section E2300 in the local mine coordinate system (indicated on Fig. 3), where there exists a potential for landslide. As can be seen in Fig. 5, the northern slope is a typical anti-dip stratified slope. The numerical model uses a length of $1100 \mathrm{~m}$ and a height of $576 \mathrm{~m}$ for the slope. The coordinate origin $O$, the horizontal $X$ direction, and the vertical $Y$ direction are marked on the schematic shown in Fig. 5. For the boundary condition, the horizontal direction of bilateral boundaries was constrained with zero displacements, the bottom boundary of the model was fixed in both the horizontal and vertical directions, and the upper boundary was free. Tables 1 and 2 summarize the physical and mechanical parameters of the rock mass and the F1 fault, respectively. The only load on the slope that was used in this analysis was the force of gravity.

The shear strength-reduction (SSR) method was adopted in this study to examine the evolution process of this toppling slope due to the following considerations. Most importantly, as joints and discontinuities will exist in a rock mass, the engineering properties in the actual field slope can be smaller than those obtained from rock samples in the lab. Also, there exist uncertainties in geo-material properties ( $\mathrm{Li}$ and Liang, 2013, 2014). Furthermore, natural forces, time-dependent rock creeping effect, and mining activities will decrease the strength of rock mass and the stability of slope (Wei et al., 2006; Rupke et al., 2007; Li et al., 2014). Moreover, SSR is not restricted to irregular geometry and material inhomogeneity of the slope. Finally, the SSR model allows a factor of safety to be obtained when the condition of slope failure is reached.

The Mohr-Coulomb constitutive model was used in the shear strength reduction process. The concept of SSR in the numerical simulation of a slope is to gradually decrease the strength parameters, cohesion $c$ and internal friction angle $\phi$, while the other physical and mechanical parameters remain unchanged. The original slope strength parameters ( $c$ and $\tan \phi$ ) are reduced incrementally by dividing them by the same reduction factor, given as:

$c_{R}=c / K$

$(\tan \phi)_{R}=\tan \phi / K$ where $K$ is the reduction factor, $c_{R}$ is the reduced cohesion, and $(\tan \phi)_{R}$ is the reduced tangent of the internal friction angle. It was assumed that all rock mass strength parameters were decreased little by little as $K$ increased gradually; and the parameters were repeatedly input into the numerical models to analyze the deformation of the slope. The smallest reduction factor corresponding to a state of slope failure is defined as the factor of safety for the slope. Currently, there are three general criteria in defining the condition of slope failure: 1) the displacement mutation characteristics of slope monitoring points, 2) the computational divergence, and 3 ) the transfixion situation of the plastic zone (Liang et al., 2014). In this study, the first criterion to find the displacement mutation of selected points with the increase of the reduction factor was used as a failure criterion.

A slope created by surface mining is usually steeper and more unstable than a slope created under a natural process in the same rock type. The open pit slope is influenced significantly by various external forces and changes in the groundwater content (Wei et al., 2006), and it undergoes quite rapid stress changes during mining (Harries et al., 2009). All of these factors will decrease the strength of rock mass. Therefore, after the failure state of the slope was reached in the numerical model, in order to further analyze the subsequent slope toppling failure mode, the shear strength parameters ( $c$ and $\phi$ ) continued to be reduced until the numerical model was completely destroyed. The slope failure mode and the horizontal displacement $U_{x}$, the vertical displacement $U_{y}$, and the total displacement $U$ of five selected monitoring points were recorded sequentially during the strength reduction process.

The five monitoring points on the northern slope were arranged along the slope surface and their local location coordinates were $A$ $(881,76)$, B $(673,-5)$, C (508, - 68), D (442, - 138), E (332, - 235), as shown in Fig. 5. Based on the horizontal displacement $U_{x}$ and the vertical displacement $U_{y}$, the total displacement $U$ can be obtained by the following equation:

$U=\sqrt{U_{x}^{2}+U_{y}^{2}}$

These recorded displacements were analyzed and compared to determine how they change during the process of slope instability.

\subsection{Continuous monitoring with GB-InSAR}

Routine monitoring methods have several limitations, which can include an insufficient number of monitoring points, or an excessively long time interval between two sampling dates. It is difficult to ensure consistency and accuracy of the data, and this can lead to failure in controlling the slope deformation or effectively managing emergency conditions. For such a huge open pit mine as the one in Fushun, the IBIS-M GB-InSAR system (developed by IDS Ingegneria Dei Sistemi $\mathrm{SpA}$ ), one of the world's most advanced monitoring systems, was installed at the site. It can continuously, comprehensively, quickly, and accurately monitor slope displacement and deformation to guarantee safety during production. The primary advantages of GB-InSAR are continuous areal monitoring, long-range operability, high pixel resolution and the ability to provide reliable early warning alerts of instability and allow maps showing the long-term evolution of slope movements to be produced. In addition, GB-InSAR has been tested in harsh mining environments, and the radar waves were found to adequately penetrate through dust, smoke, and rain in the field. Details regarding the principles and applications of this system are provided in Bozzano et al. (2008, 2011).

Table 3

Instrumental configuration of IBIS-M.

\begin{tabular}{|c|c|c|c|c|c|c|c|}
\hline Range resolution & Cross-range resolution & Central frequency & Nominal accuracy & Measurement time interval & Azimuth & Scan geometry & Rail length \\
\hline $0.5 \mathrm{~m}$ & $4.3 \mathrm{mrad}$ & $16.75 \mathrm{GHz}$ & $0.1 \mathrm{~mm}$ & $9 \mathrm{~min}$ & $4.94^{\circ}$ & linear & $2 \mathrm{~m}$ \\
\hline
\end{tabular}



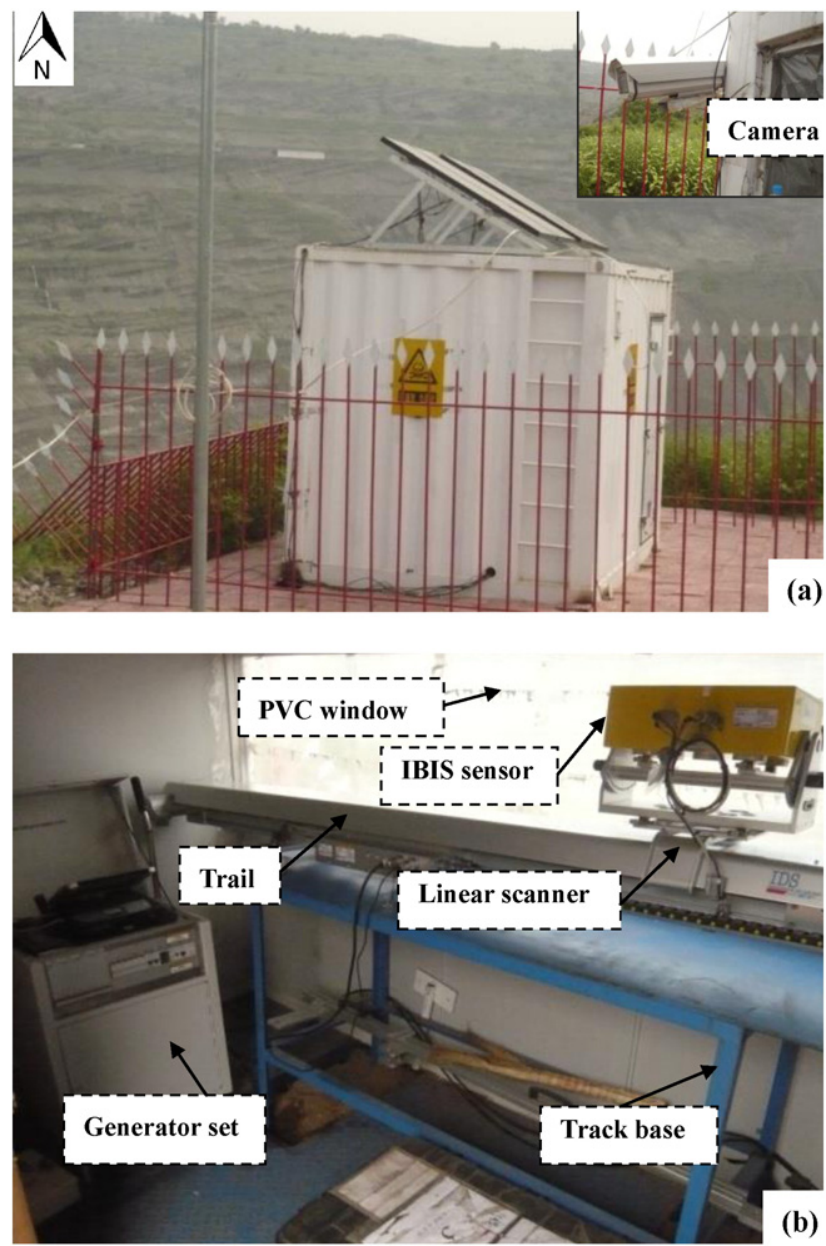

Fig. 6. IBIS-M remote radar monitoring platform a) outside view and b) inside view.

According to the site topography of the Fushun open pit mine, the integrated radar monitoring platform was placed on the southeast wall E2440 in the local mine coordinate system. The monitoring area of the northern wall, indicated on Fig. 3, is an area where there is the potential for landslides that could pose a hazard to personnel and equipment. The monitoring device can target distance up to $4000 \mathrm{~m}$ and the monitoring area can reach up to several square kilometers. However, due to the special site topography, only the width of $1600 \mathrm{~m}$ in the northern wall was monitored. The distance from the device to the measured slope was from $500 \mathrm{~m}$ to $1200 \mathrm{~m}$. The instrumental configuration of IBIS-M is listed in Table 3.

The IBIS-M remote radar monitoring platform was housed in a specially designed box (Fig. 6). A digital camera was used to acquire images continuously, and information was transferred automatically to the controlling computer. The computer is used to calculate the phase difference between all the pixels of continuous SAR maps obtained at different times. Both the cumulative displacement map and the deformation velocity map can be generated from GB-InSAR data by the controlling computer (Bozzano et al., 2011). Fig. 7 illustrates the entire monitoring slope area collected by IBIS-M.

\section{Results and discussion}

\subsection{Simulated toppling failure}

The strength parameters of the northern slope were reduced gradually with an increase in the strength reduction factor. The toppling deformation mode was recorded during the strength reduction process. The deformation evolution process from stability to instability can be divided into three stages:

\section{Stage 1: Stable state}

In the comparatively stable state, no apparent deformation characteristics were observed in the slope or on the surface of the slope. Stage 1 corresponded to $K<1.4$.

Stage 2: Development

In this stage, prior to the occurrence of failure plane, some fissures developed in the anti-dipping layered part of the slope. For clearer observations, the deformation position is illustrated in Fig. 8. This stage corresponded to $K=1.4$ and $K=1.5$.

Stage 3: Initial failure state

In the third stage, the failure state suddenly appeared when the reduction factor $K$ was between 1.5 and 1.6. The initial failure mode is depicted in Fig. 9. As we can see, an apparent crack and some fractures were observed in the lower part of the slope during the initial damage stage. This crack exhibited a linear shape. Unlike the circular

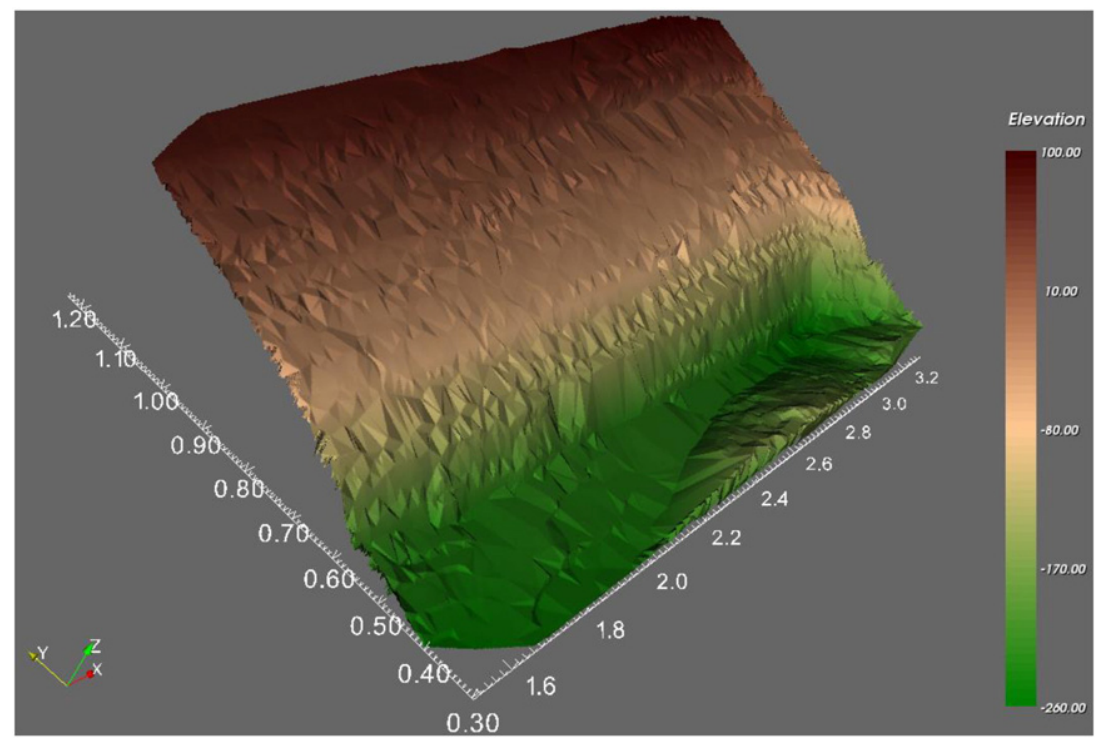

Fig. 7. Monitoring area of the northern wall of Fushun open pit (X-Y axes unit: kilometer, elevation unit: meter). 


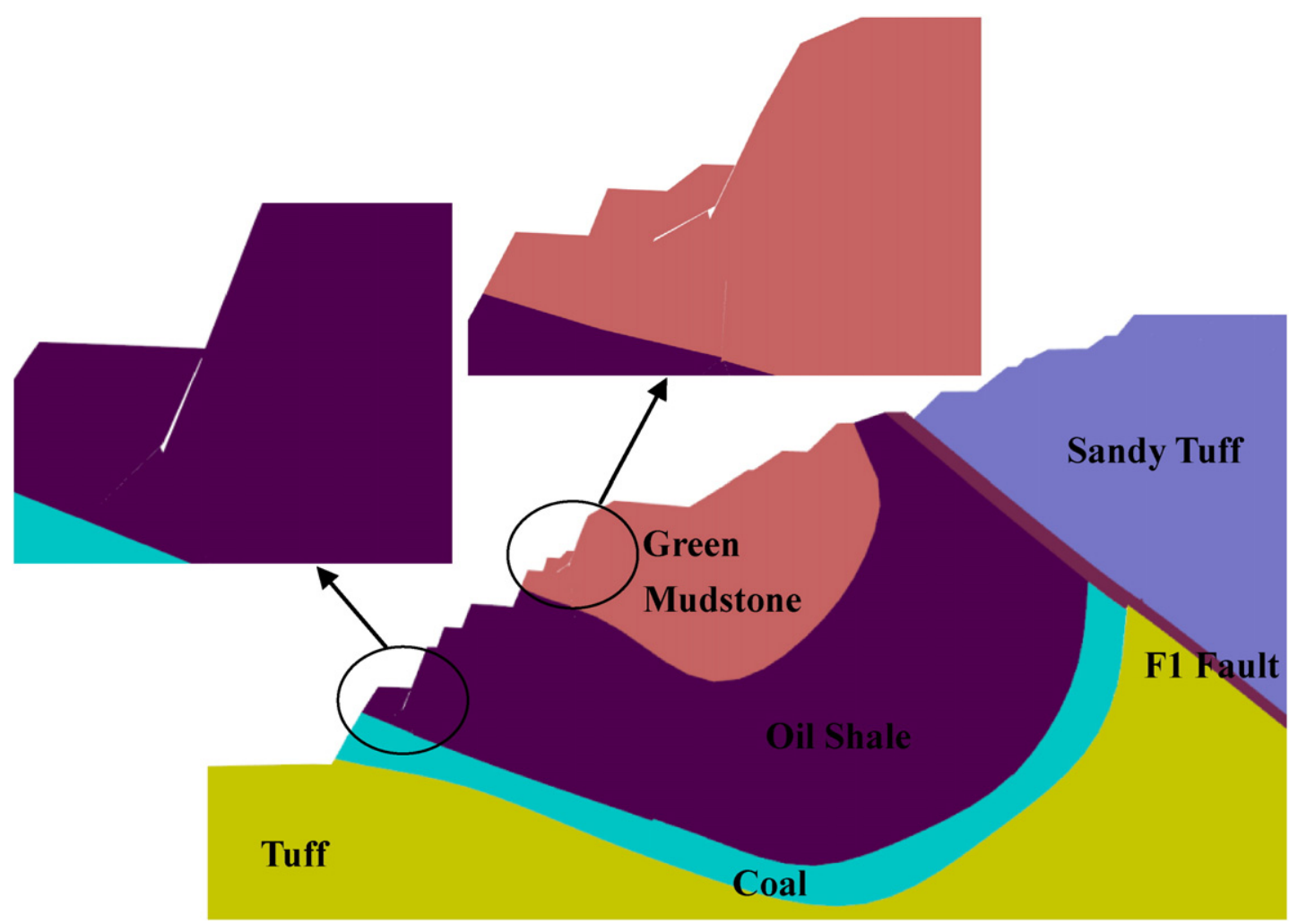

Fig. 8. Deformation diagram of the second stage of the simulated toppling failure process.

slip failure mode, the toppling failure mode was formed due to the slope's geological structure. According to the limiting equilibrium method, the fundamental assumption for the existence of the limiting equilibrium state is that the "base plane" inclines at a specific angle to the normal to the rock layer dip angle (Aydan and Kawamoto, 1992). This linear crack formed in the anti-dip portion of the slope, and it validated the "base plane" assumption well.
The displacement changes of the five monitoring points with respect to the increase of reduction factor are depicted in Fig. 10. It can be seen that when $K<1.5$, the displacement lines of the monitoring points leveled off, indicating that the slope was relatively stable. When $K$ increased to 1.6, there were distinct mutations for the horizontal displacement, vertical displacement and total displacement of points $C, D$, and $E$. The changes in displacement for points $A$ and $B$ were relatively small

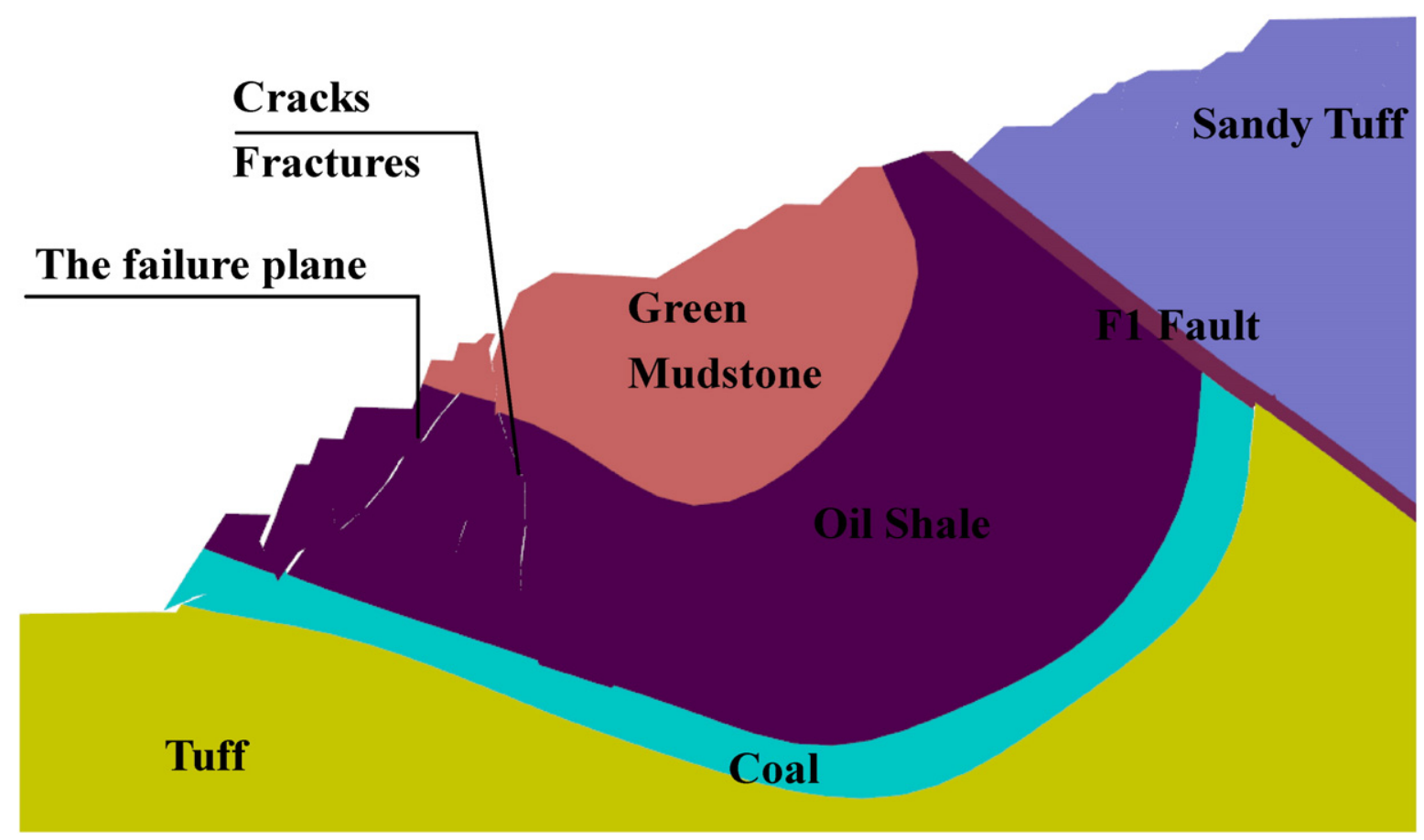

Fig. 9. Initial failure state of Fushun northern slope. 

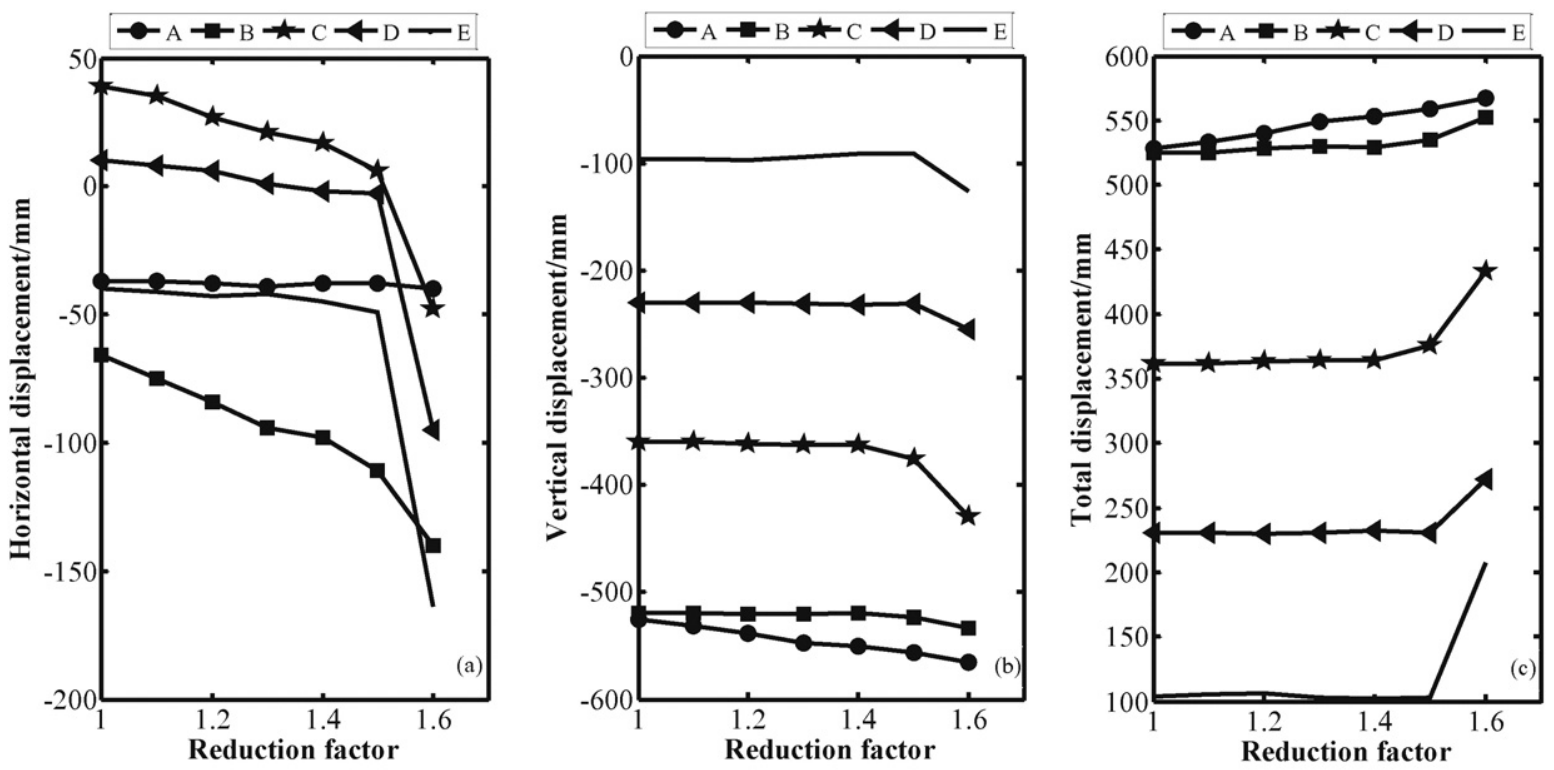

Note: “+"indicates horizontal or vertical displacement in the positive direction; “-"indicates horizontal or vertical displacement in the negative direction; the direction of total displacement is not considered herein.

Fig. 10. Relationship between the reduction factor and a) horizontal displacement; b) vertical displacement; and c) total displacement.

and without apparent mutations. There are three possible reasons may account for this. Firstly the lower part of the slope below point $C$ was a typically anti-dipped feature. Another contributing factor is that point $A$ and $B$ were located at relatively hard rock, and hard rock would exert impacts on the lower soft rock. Also, the slope gradient of $A, B$ was comparatively small, while that of $C, D, E$ was relatively large. With these slope characteristics, the steep lower part of the slope was prone to topple as illustrated in Fig. 9. According to the evolution of slope deformation and the movement monitoring results, the appropriate strength reduction factor $K=1.6$ was determined to be the slope safety factor.

Based on the previous observations and the geological setting at the site, three stages of toppling deformation for Fushun open pit slope have been identified. In Stage 1, even though there were no obvious deformation characteristics observed in the northern slope, various joints and discontinuities had already formed in the slope due to the F1 fault according to the geological setting. In addition, groundwater motion was active at the site, as had been observed in the field investigation. It was favorable for groundwater to migrate into the lower plate of the F1 fault due to the existing joints and discontinuities. Moreover, it was difficult for the groundwater to discharge owing to the inward dipping slope structure and the relative impermeability of the green mudstone formation. The rock could be softened, greatly decreasing the strength of the rock mass, which would cause slope deformation to develop into Stage 2. In addition, a large amount of rainfall could be one of the dominant contributing factors to the initial failure of the slope (Stage 3 ), because high hydrostatic and hydrodynamic pressures were generated by atmospheric precipitation infiltration into the slope through the fissures (Huang et al., 2013). This speculation was verified by the monitoring results obtained by GB-InSAR.

\subsection{Validation with monitoring results and field observation}

The monitoring platform was installed in June 2012. Use of GBInSAR at the northern wall of Fushun open pit has led to the detection of the slope deformation characteristics from July 2012 to September 2012. This time period corresponds to the flood season in the Fushun area, when significant rainfall accumulations are experienced. The maximum daily rainfall could be as high as $185.9 \mathrm{~mm}$ /day and the maximum continuous rainfall could be as much as $263.5 \mathrm{~mm}$. Fig. 11a shows the location of recorded deformation region within the whole monitored area and Fig. 11b and c show the slope deformation line-of-sight (LOS) velocity maps at the captured moment on July 25, 2012 and September 23, 2012, respectively. The regions with different speeds can be displayed using different colors and levels; the areas shown in red are those with high velocity, and areas in green are those with low velocity. The greater the speed, the more quickly the slope moved at that moment. The warning speed value can be set so that if the monitored velocity exceeds a threshold value, it will trigger an alarm and will indicate the area with dangerous conditions. As can be noticed, there was a zone at the lower western slope that was moving quickly toward the outside of the slope. The speed of the area in red (E2283-E2343) exceeded the warning value of $2 \mathrm{~mm} / \mathrm{h}$, while the other green regions of the slope were in the low-velocity zone. As time went on, the red area increased, indicating that the slope movement area with a large speed had increased. Based on the field investigation, we found potential threats around E2300 of the northern wall. Consequently, the red area (E2283-E2343) shown in Fig. 11c was identified as a dangerous zone.

As the analysis of velocity change trend in a slope could provide an effective basis for evaluating the slope's stability, the average speed of the dangerous zone (E2283-E2343) was recorded during the flood season (Fig. 12). The horizontal axis displayed the time and the vertical axis displayed the velocity values. It can be seen that the average velocity of the entire dangerous zone fluctuated in the monitoring period at rates that were for the most part less than $9 \mathrm{~mm} / \mathrm{h}$. At some specific times, mutations for speed were found that reached extremes, indicating that slippage had occurred to some degree at the corresponding time. Afterward, the average speed began to decrease. This process occurred especially when there was an evident peak for the recorded speed curve. The slope movement was found to increase suddenly to a speed of $17 \mathrm{~mm} / \mathrm{h}$. In the period of late August to early September, there was continuous intense rainfall in the Fushun region, which resulted in the instability of the open pit slope and an increased risk of landslides. 

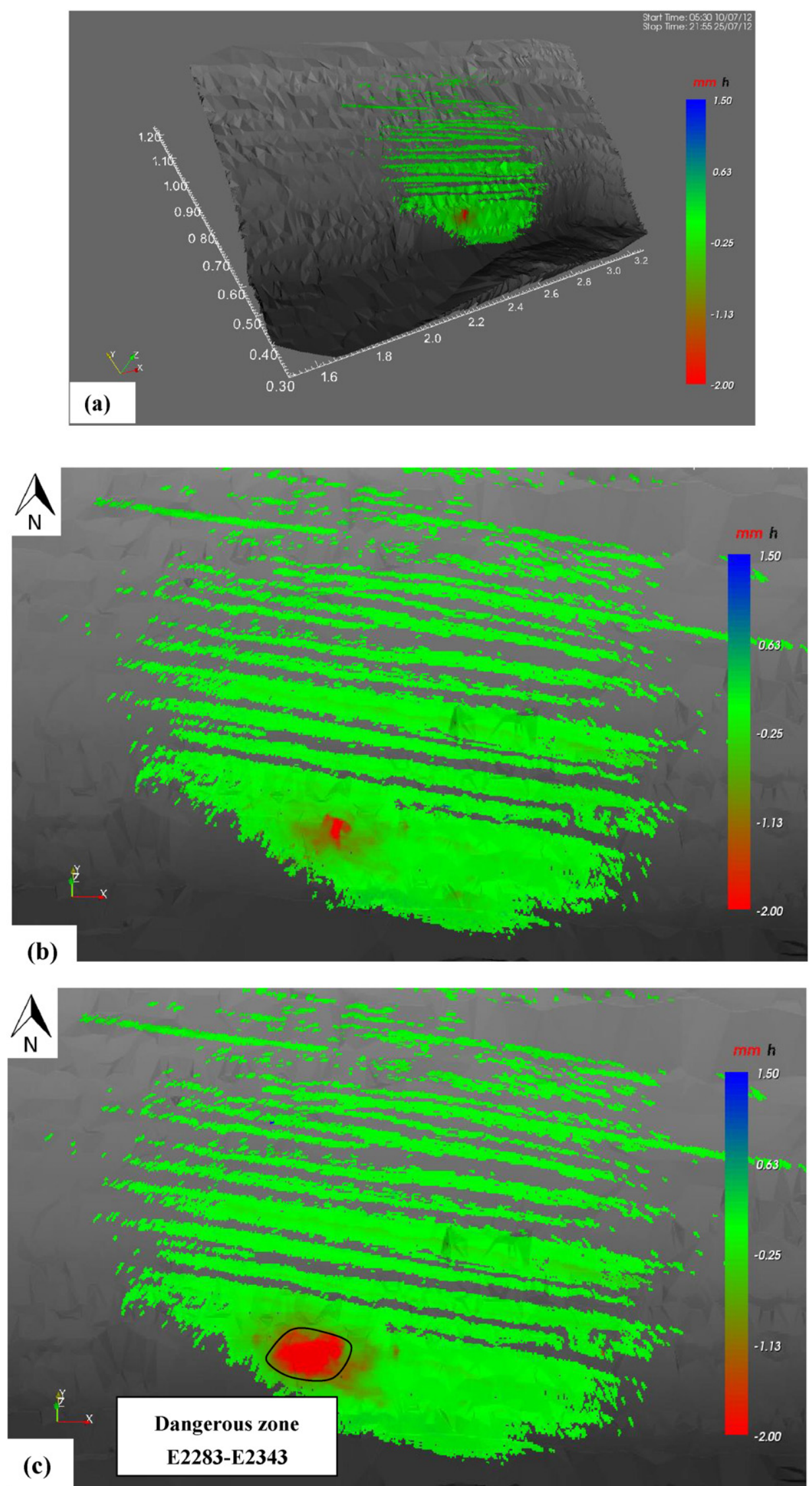

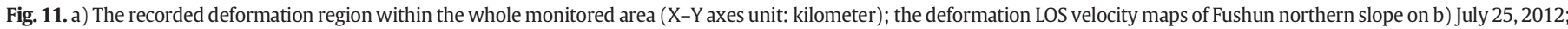
and c) September 23, 2012. 


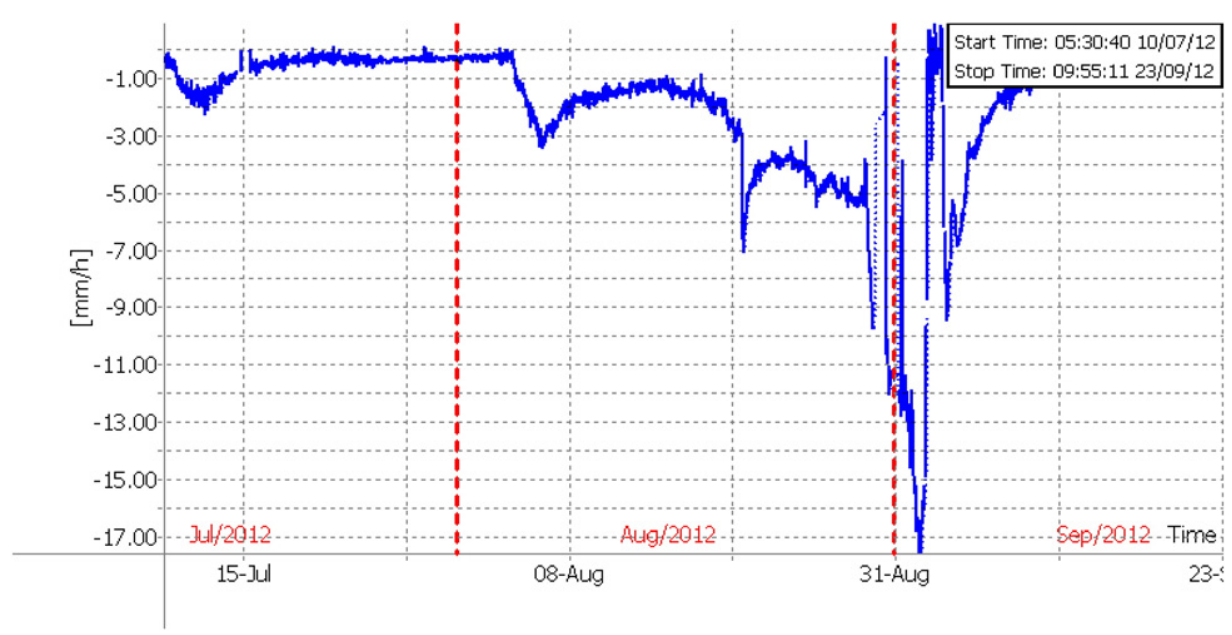

Fig. 12. Time series of average speed of the dangerous zone from July 10, 2012 to September 23, 2012 (blue line) and time boundary for each month (red dash line).

After intense rainfall, large-scale rib spalling and falling blocks were observed around E2300 of the northern wall, in an area that was approximately $23 \mathrm{~m}$ wide and $5 \mathrm{~m}$ high. The rib spalling area was found at an elevation of $-231 \mathrm{~m}$ and encompassed an area of approximately 100 square meters.

The displacement pattern of the northern slope was also recorded during the flood season. Fig. 13 shows a comparison between the cumulative displacement map obtained from GB-InSAR during the period 10 July-23 Sept, 2012 and the field observations. For the radar displacement map, the blue region represents displacement toward the interior of the slope, the green region represents a relatively stable area, and the red region represents displacement toward the outside of the slope. As can be seen in Fig. 13, the radar monitoring results were consistent with the field conditions, and the displacement map was able to reflect the regions where rib spalling and blocks falls occurred (as indicated by the red area). The main failure was located at the lower western part of the slope, in an area that was just within the dangerous zone (E2283-E2343) where the slope experienced high-velocity movement.

The numerical model built by CDEM was based on the cross-section E2300, which was within the dangerous zone (E2283-E2343) identified through the use of GB-InSAR data. Due to lack of strength measurement data for the failed zone prior to and during the initial failure stage, no direct comparison was conducted to verify the critical reduction factor
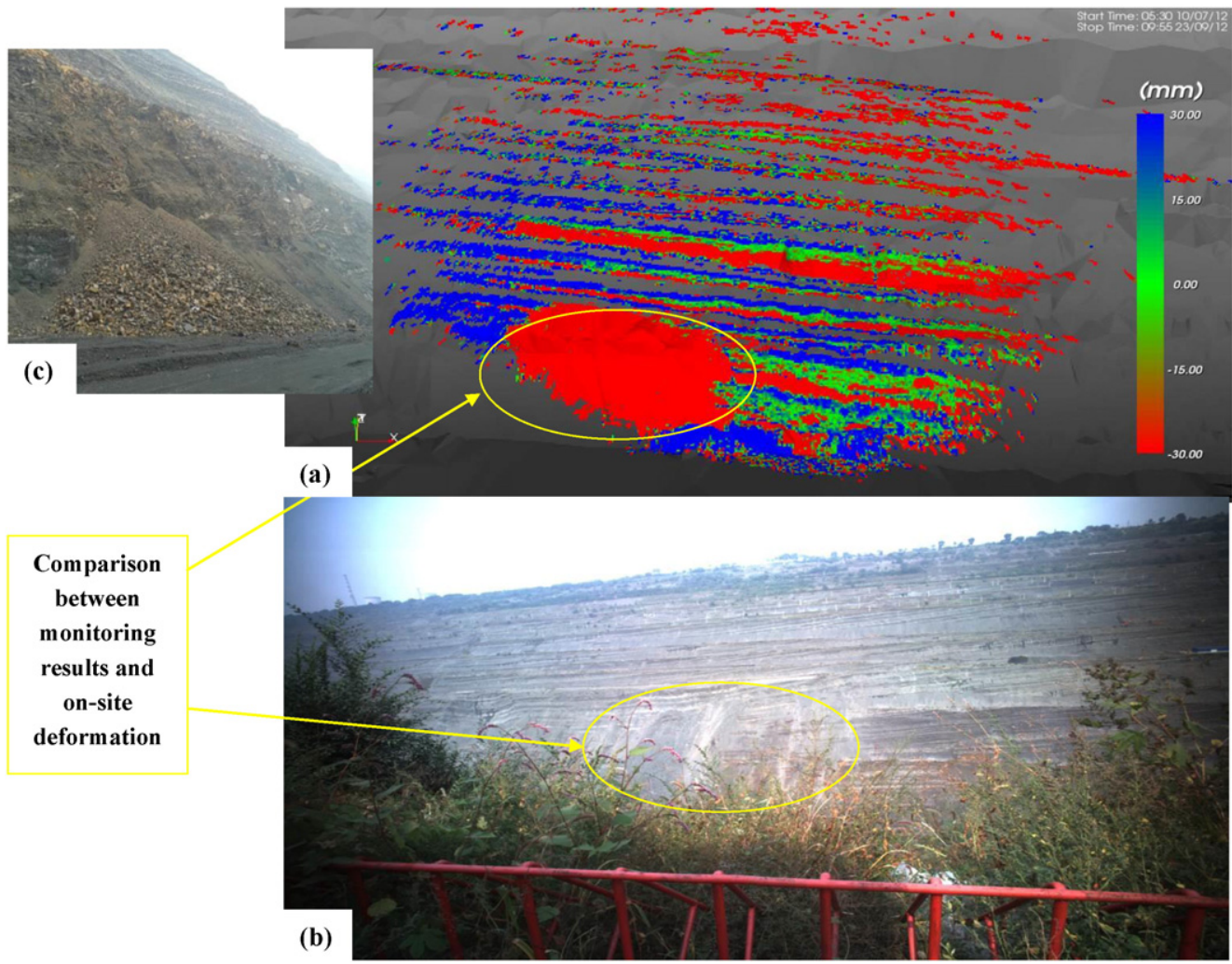

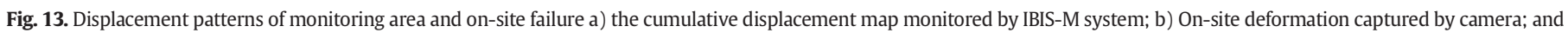
c) Sliding mass deposition in the field. 

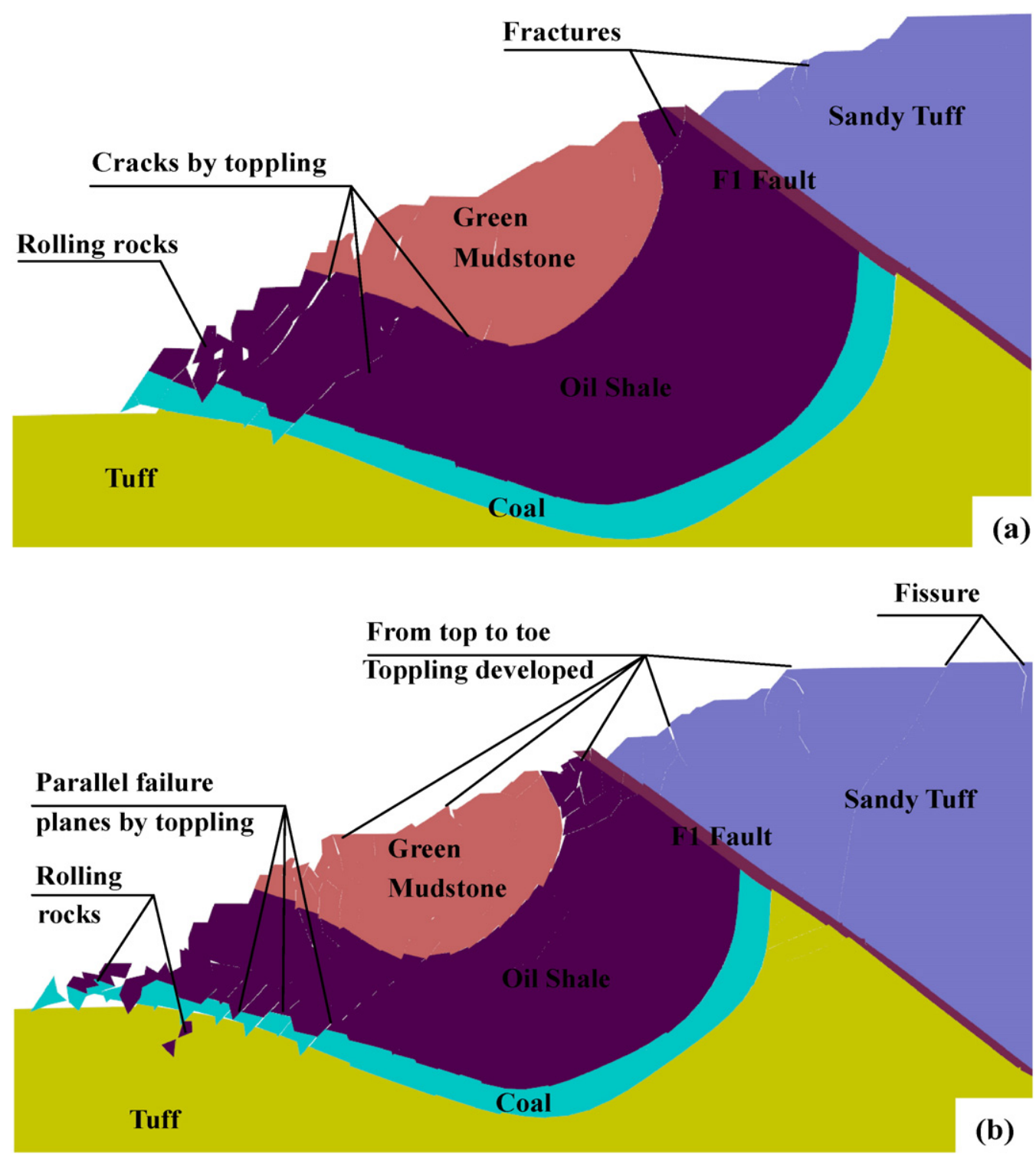

Fig. 14. Subsequent failure state of the northern wall of Fushun open pit: a) $K=2.0$; and b) $K=3.0$.

with actual observations. Alternatively, the IBIS-M monitoring data of ground movement and the actual failure morphology of the Fushun northern slope validated the estimated initial failure state by CDEM. The slope was not stationary; it kept moving, and the deformation and displacement increased with time. This calibration did provide some credibility to the model capability, thus it allows using the CDEM model to investigate the progressive toppling deformation characteristics as the strength reduction factor is successively increased.

\subsection{Prediction of subsequent toppling evolution}

With a large-scale engineered slope such as the one considered in this study, external forces from mining activities (such as blasting vibration, unloading, excavation, and construction.) will greatly decrease the slope stability. These mining activities are expected to reduce rock mass strength and alter the internal stress state of the slope, causing already existing inner joints to extend and discontinuities to develop, and perhaps promote new fissures in the rock. In addition, creep deformation could be initiated. Therefore, the subsequent toppling mode was predicted with a further reduction in rock strength. When $K=2.0$ (as shown in Fig. 14a), a greater number of shear cracks and fractures developed in the lower part of slope, and some fissures were observed in the green mudstone. No obvious deformation characteristics were found in the upper part of the slope. When $K$ increased to 3.0 (Fig. 14b), complete toppling failure occurred. Crushed blocks, distinct dislocation, and large-scale slope surface slippage were observed near the toe of the slope, and fresh fractures were found through the green mudstone, near the crest and around the F1 fault, and an evident tension crack was formed at the top right in this slope model. In addition, a number of linear cracks that were almost equidistantly parallel to the initial failure plane were observed in the anti-dipping structure. This finding further validated the basic assumption in the limiting equilibrium method.

During the progressive evolution process of the Fushun northern slope, the rock mass bends under the influence of gravity and the rocks will break in flexure as they bend forward. Deformation and failure will begin at the lower anti-dip portion of the slope. The initial failure will exert strong impacts and will retrogress backward (Goodman and Bray, 1976), as the impact of the rolling broken rocks will initiate more shearing cracks. The subsequent failure mechanism of toppling is similar to the initial failure mechanism. When the internal tensile stress reaches the tensile strength, a series of new tension cracks 
will be induced. Thus, slope toppling deformation is the combined effect of bending and shear, which results in overall anti-dip slope failure.

\section{Summary and conclusions}

In this study, a typical large-scale anti-dip engineered slope with a weak cutting-through failure has been analyzed. Flexural toppling was investigated through a case study that considers the deformation characteristics, the failure mechanism and the evolution process. Meanwhile, a novel numerical method known as the continuum-based discrete element method (CDEM) was introduced to model the flexural toppling. The shear-strength reduction (SSR) method was adopted to describe the strength reduction of rock mass due to natural geological factors and the effects of human activities during the evolution process of the northern slope of Fushun Open Pit. The simulated results were validated using the actual monitoring results from an advanced GB-InSAR radar technique and the field investigation. Finally, the future subsequent toppling failure mode of this slope was successfully predicted. Specific conclusions based on the CDEM and field monitoring can be made as follows:

1) A method combining CDEM and SSR was proved to be successful in describing the toppling deformation characteristics and failure evolution of this anti-dip engineered slope. The original failure plane observed in the anti-dip part of slope was consistent with the assumptions made in the limiting equilibrium method.

2) The recorded displacement and velocity patterns monitored by the remote radar technique GB-InSAR coincided with the numerical results. The zone E2283-E2343 at the lower part of this slope was observed to move quickly between the end of August 2012 and the beginning of September 2012 and to reach $17 \mathrm{~mm} / \mathrm{h}$, which indicated rib spalling and falling blocks in this zone at the corresponding time due to intense rainfalls.

3) The unique geological structure of the site had various joints and discontinuities, groundwater activity, intense rainfall, and mining activities that were identified as the main contributing factors to different failure stages. If the deterioration of the rock strength is affected by the above factors, the subsequent failure modes can be predicted. A series of parallel failure planes, cataclastic rocks, and sliding mass would be formed in the anti-dipping structure, with more shear cracks and fractures being developed in the slope rock mass and at the slope surface.

An expansion of the numerical simulations that incorporates different degrees of reduction in rock mass strength, various joints and discontinuities, and groundwater activity would be an effective extension of the analysis in this study. Moreover, with better monitoring maps that incorporate slope deformation data acquired over a longer time period and by combining the GB-InSAR data with topographic data and underground mining maps, it would be possible to gain a more complete understanding of the overall dynamics of a large-scale engineered slope.

\section{Acknowledgments}

The generous support of the National Basic Research Program of China (973 Program, 2010CB731501), National Natural Science Foundation of China (No. 41172264) and University of Science and Technology Beijing, P.R. China, is gratefully acknowledged. Computer hardware and software, GDEM, were provided by Institute of Mechanics, Chinese Academy of Sciences. And Fushun Mining Group Co., Ltd. Xilutian Open Mine provided valuable field data and allows data to be used in the study.

\section{References}

Adhikary, D.P., Dyskin, A.V., 2007. Modelling of progressive and instantaneous failures of foliated rock slopes. Rock Mech. Rock. Eng. 40 (4), 349-362.

Adhikary, D.P., Dyskin, A.V., Jewell, R.J., 1996. Numerical modelling of the flexural deformation of foliated rock slopes. Int. J. Rock Mech. Min. Sci. Geomech. Abstr. 33 (6), 595-606.

Adhikary, D.P., Dyskin, A.V., Jewell, R.J., Stewart, D.P., 1997. A study of the mechanism of flexural toppling failure of rock slopes. Rock Mech. Rock. Eng. 30 (2), 75-93.

Alejano, L.R., Gómez-Márquez, I., Martínez-Alegría, R., 2010. Analysis of a complex toppling-circular slope failure. Eng. Geol. 114, 93-104.

Amini, M., Majdi, A., Aydan, O., 2009. Stability analysis and the stabilization of flexural toppling failure. Rock Mech. Rock. Eng. 42, 751-782.

Aydan, O., Kawamoto, T., 1992. The stability of slopes and underground opening against flexural toppling and their stabilization. Rock Mech. Rock. Eng. 25 (3), 143-165.

Bozzano, F., Mazzanti, P., Prestininzi, A., 2008. A radar platform for continuous monitoring of a landslide interacting with an under-construction infrastructure. Ital. J. Eng. Geol. Environ. 2, 71-87.

Bozzano, F., Cipriani, I., Mazzanti, P., Prestininzi, A., 2011. Displacement patterns of a landslide affected by human activities: insights from ground-based InSAR monitoring. Nat. Hazards 59, 1377-1396.

Bray, J.W., Goodman, R.E., 1981. The theory of base friction models. Int. J. Rock Mech. Min. Sci. Geomech. Abstr. 18, 53-468.

Colesanti, C., Wasowski, J., 2006. Investigating landslides with space-borne synthetic aperture radar (SAR) interferometry. Eng. Geol. 88, 173-199.

Fernandez, P., Irigaray, C., Jimenez, J., El Hamdouni, R., Crossetto, M., Monserrat, O., Chacon, J., 2009. First delimitation of areas affected by ground deformations in the Guadalfel River Valley and Granada metropolitan area (Spain) using the DInSAR technique. Eng. Geol. 105, 84-101.

Goodman, R.E., Bray, J.W., 1976. Toppling of rock slopes. Proceedings: ASCE Specialty Conference, Rock Engineering for Foundations and Slopes, Boulder, Colorado vol. 2, pp. 201-234.

Hack, R., Alkema, D., Kruse, G.A.M., Leenders, N., Luzi, L., 2007. Influence of earthquakes on the stability of slopes. Eng. Geol. 91, 4-15.

Harries, N., Noon, D., Pritchett, H., 2009. Slope stability radar for managing rock fall risks in open cut mines. Proceedings: the 3rd CANUS rock mechanics symposium (ROCKENG09), Toronto, Canada, May 2009, paper 4279.

Herrera, G., Tomas, R., Lopez-Sanchez, J.M., Delgado, J., Mallorqui, J.J., Duque, S., Mulas, J., 2007. Advanced DInSAR analysis on mining areas: La Union case study (Murcia, SE Spain). Eng. Geol. 90, 148-159.

Huang, R.Q., Zhao, J.J., Ju, N.P., Li, G., 2013. Analysis of an anti-dip landslide triggered by the 2008 Wenchuan earthquake in China. Nat. Hazards 68, 1021-1039.

Li, L., Liang, R.Y., 2013. Reliability-based design for slopes reinforced with a row of drilled shafts. Int. J. Numer. Anal. Methods Geomech. 38, 202-220.

Li, L., Liang, R.Y., 2014. Limit equilibrium based design approach for slope stabilization using multiple rows of drilled shafts. Comput. Geotech. 59, 67-74.

Li, S.H., Zhao, M.H., Wang, Y.N., Wang, J.G., 2004a. A continuum-based discrete element method for continuous deformation and failure process. Proceedings: the 6th world congress on computational mechanics in conjunction with the Second AsianPacific Congress on Computational Mechanics, Beijing, China, 5-10 Sept. 2004, paper 77.

Li, S.H., Zhao, M.H., Wang, Y.N., Rao, Y., 2004b. A new numerical method for DEM-block and particle model. Int. J. Rock Mech. Min. Sci. 41 (3), 436-440.

Li, S.H., Lian, Z.Z., Wang, J.G., 2005. Effect of rock mass structure and block size on the slope stability-physical modeling and discrete element simulation. Sci. China Ser. E Eng. Mater. Sci. 48, 1-17 (Suppl.).

Li, S.H., Wang, J.G., Liu, B.S., Dong, D.P., 2007. Analysis of critical excavation depth for a jointed rock slope using a face-to-face discrete element method. Rock Mech. Rock. Eng. 40 (4), 331-348.

Li, L., Liang R.Y., Liu, H.L., 2014. System reliability analysis for anchor-stabilised slopes considering stochastic corrosion of anchors. Struct. Infrastruct. Eng. http://dx.doi. org/10.1080/15732479.2014.963626.

Liang, R.Y., Joorabchi, A.E., Li, L., 2014. Analysis and design method for slope stabilization using a row of drilled shafts. J. Geotech. Geoenviron. Eng. ASCE 140 (5), 04014001.

Perski, Z., Hanssen, R., Wojcik, A., Wojciechowski, T., 2009. InSAR analyses of terrain deformation near the Wieliczka Salt Mine, Poland. Eng. Geol. 106, 58-67.

Pritchard, M.A., Savigny, K.W., 1990. Numerical modeling of toppling. Can. Geotech. J. 27, 823-834.

Rupke, J., Huisman, M., Kruse, H.M.G., 2007. Stability of man-made slopes. Eng. Geol. 91, $16-24$.

Tomas, R., Herrera, G., Delgado, J., Lopez-Sanchez, J.M., Mallorqui, J.J., Mulas, J., 2010. A ground subsidence study based on DInSAR data: Calibration of soil parameters and subsidence prediction in Murcia City (Spain). Eng. Geol. 111, 19-30.

Tu, X.B., Dai, F.C., Lu, X.J., Zhong, H.Y., 2007. Toppling and stabilization of the intake slope for the Fengtan Hydropower Station enlargement project, Mid-South China. Eng. Geol. 91, 152-167.

Wang, Y.N., Zhao, M.H., Li, S.H., Wang, J.G., 2005. Stochasitc structural model of rock and soil aggregates by continuum-based discrete element method. Sci. China Ser. E Eng. Mater. Sci. 48, 95-106 (Suppl.)

Wang, L.X., Li, S.H., Zhang, G.X., Ma, Z.S., Zhang, L., 2013. A GPU-based parallel procedure for nonlinear analysis of complex structures using a coupled FEM/DEM approach. Math. Probl. Eng. 2013, 618980.

Wei, Z.A., Li, S.H., Wang, J.G., Wan, L., 2006. A dynamic comprehensive method for landslide control. Eng. Geol. 84, 1-11. 
Wong, R.H., Chiu, M., 2001. A study on failure mechanism of toppling by physical model testing. Proceedings: 38th U.S. Rock Mechanics Symposium. Washington, D.C., USA, pp. 989-995.

Yang, T.H., Rui, Y.Q., Tang, C.A., Li, L.C., Shen, L., 2004. Study on deformation features and dynamic stability of creeping slope of Fushun West Strip Mine. Rock Soil Mech. 25 (1), 153-156 (in Chinese).
Zhang, L., Wei, Z.A., Liu, X.Y., Li, S.H., 2005. Application of three-dimensional discrete element face-to-face contact model with fissure water pressure to stability analysis of landslide in Panluo iron mine. Sci. China Ser. E Eng. Mater. Sci. 48, 146-156 (Suppl.). 